\title{
Imaging Diagnosis in Colorectal Endometriosis
}

\author{
Marina Rodica ANTONOVICI ${ }^{1}$, Oana Maria IONESCU ${ }^{1}$, Horace ROMAN² , Claudia MEHEDINTU
}

\begin{abstract}
Colorectal deep infiltrative endometriosis (DIE) can have a major impact on patient's health and quality of life. Surgical treatment of colorectal DIE varies depending on the location and characteristics of the lesions, which is why the preoperative non-invasive diagnosis needs to be correct and complete. Multiple imaging methods are currently available, but their usefulness is still being studied, as none of them has proven itself perfect. In the present study we wanted to find out to what extent the combined use of magnetic resonance imaging (MRI), endorectal ultrasound (ERUS) and computed tomography-based virtual colonoscopy (CTC) helps perform the preoperative mapping of lesions. We conducted a retrospective study of prospectively collected data that included 49 patients operated for colorectal DIE. In identifying rectal nodules, MRI as a single diagnostic method was the most useful. When ERUS or CTC was added, the concordance between intraoperative and imaging results was very strong. CTC was the most useful in identifying sigmoid nodules. ERUS evaluates the depth of rectal nodules best. CTC assesses best the stenosis for both rectal and sigmoid nodules. Each method contributed to the completion of the diagnosis, so performing ERUS and CTC in addition to MRI seems to be preferable in patients with colorectal DIE.
\end{abstract}

Keywords: colorectal endometriosis, endorectal ultrasonography, MRI, computed tomography-based virtual colonoscopy.

\section{Rezumat}

Endometrioza profund infiltrativă (EPI) colorectală poate avea un impact major asupra sănătății și calității vieții pacientelor. Tratamentul chirurgical al EPI colorectale variază în funcție de localizarea și caracteristicile leziunilor, motiv pentru care diagnosticul non-invaziv preoperator se dorește a fi corect și complet. Multiple metode imagistice sunt disponibile în prezent, dar utilitatea lor este încă studiată, deoarece niciuna nu s-a dovedit perfectă. în prezentul studiu am dorit să aflăm în ce măsură utilizarea combinată a imagisticii prin rezonanță magnetică (IRM), ecografiei endorectale (EER) și colonoscopiei virtuale asistată computer tomografic (CTC) ajută la realizarea mapping-ului preoperator al leziunilor. Am realizat un studiu retrospectiv al datelor colectate prospectiv, ce a inclus 49 de paciente operate de EPI colorectală. În identificarea nodulilor rectali, ca metodă singulară de diagnostic, IRM a fost cel mai util. Când s-au adăugat EER sau CTC concordanța dintre rezultatele intraoperatorii și cele imagistice a fost foarte puternică. Pentru nodulii sigmoidieni cel mai util s-a dovedit CTC. EER evaluează profunzimea nodulilor rectali cel mai bine. CTC evaluează cel mai bine stenoza atât pentru nodulii rectali cât și pentru cei sigmoidieni. Fiecare metodă a contribuit la completarea diagnosticului. Astfel, efectuarea pe lângă IRM, atât a EER cât și a CTC pare să fie de preferat, în cazul pacientelor cu EPI colorectală.

Cuvinte cheie: endometrioză colorectală, ecografie endorectală, IRM, colonoscopie virtuală asistată computer tomografic.

${ }^{1}$ "Carol Davila" University of Medicine and Pharmacy, Bucharest, Romania

${ }^{2}$ Endometriosis Center, Clinique Tivoli-Ducos, Bordeaux, France

\section{Corresponding author.}

Oana Maria IONESCU, "Carol Davila" University of Medicine and

Pharmacy, Bucharest, Romania.

E-mail: ionescuoanamaria@gmail.com 


\section{INTRODUCTION}

Endometriosis, an estrogen dependent pathology, is characterized by the presence of endometrial-like tissue outside the uterine cavity ${ }^{1}$. There are 3 types of endometriotic lesions: ovarian endometriosis / endometriomas, superficial peritoneal endometriosis and, when talking of invasion beyond $5 \mathrm{~mm}$ from the peritoneal surface, deep infiltrating endometriosis (DIE) $)^{2-4}$. DIE in mostly localized in the rectovaginal septum, uterosacral ligaments, Douglas pouch, or affecting the near organs like small bowels, colon, ureters or urinary bladder 3,4. Colorectal DIE can become very aggressive, and it can lead to serious impairment of a woman's health and quality of life due to its associated complaints such as diarrhea, constipation, tenesmus, dyschezia and occlusion. In $80 \%$ of cases, colorectal DIE consists of fibrotic nodules that involve the rectum and the distal sigmoid $^{5}$. Preoperative assessment of nodules localization and features are extremely important in orienting the surgical approach. In the preoperative assessment of colorectal DIE may be used multiple imagistic methods with various performances: transvaginal ultrasound (TRUS), endorectal ultrasound (ERUS), magnetic resonance imaging (MRI), computed tomography (CT), and, used more and more in the last decade, the computed tomography-based virtual colonoscopy (CTC) ${ }^{6}$.

\section{MATERIALS AND METHODS}

This is a retrospective study of prospectively collected data from January 2018 until December 2018 that included patients operated for colorectal DIE at the University Hospital of Rouen. The prospective data recording was approved by the French Advisory Committee on the Use of Data in Health Research (CCTIRS / Le Comité Consultatif sur le Traitement de l'Information en matière de Recherche dans le domaine de la Sante).

The data were collected from: the symptoms-oriented questionnaires completed by patients before surgery, clinical examination, imaging methods performed preoperatively and intraoperatively also.

Patients underwent MRI, ERUS and CTC. MRI acquisitions were performed on a $1.5 \mathrm{~T}$ system with "jelly method" endometriosis protocol $(60 \mathrm{ml}$ ultrasonographic gel in the vagina and $120 \mathrm{ml}$ in the rectum) to allow a better view of vaginal recesses, rectovaginal septum and posterior compartment. For CTC the slice thickness was $3 \mathrm{~mm}$ with a reconstruction interval of
$1.5 \mathrm{~mm}$. MRI and CTC evaluations performed outside the tertiary center were reviewed by the local radiologist to eliminate differences between evaluators.

Based on the information provided by the clinical examination and imaging methods, the senior gynecologic surgeon decided the management of the case (shaving, disc excision, colorectal resection or expectant management). He was assisted intraoperatively by a colorectal surgeon, whenever discoidal excision or colorectal resection were necessary.

For statistical analysis purposes, the following parameters were defined for intestinal nodules: length (difference between the heights of the upper and lower edges of the lesion, expressed in millimeters), width (percentage of the unfolded area of the intestine $<25 \% / 25-50 \% />50 \%$ ), depth (the layer up to which the lesion penetrates - muscularis propria / submucosa / mucosa), height (distance from the lower limit of the lesion to the anal verge, expressed in millimeters) and stenosis of the intestinal segment (reduction of the intestinal lumen determined by comparing the smallest diameter of the stricture with the closest diameter of normal intestinal lumen, expressed as percentage $<30 \%$ / 30-60\% / > 60\%). The stenosis generated and the height of the endometriotic nodule were estimated during the surgical procedure using a rectal probe with a diameter of $30 \mathrm{~mm}$, while the length, the width and the depth were evaluated postoperatively on the excised piece.

All cooperating patients over 18 years of age, with symptoms suggestive for colorectal endometriosis, who completed the preoperative evaluation questionnaire, who signed informed consent, both for surgery and for inclusion in the research database, who performed all three imaging investigations (MRI, CTC and ERUS) and which were operated for colorectal DIE, were included in the research.

The correlation between the intraoperative aspects and the results of the imaging techniques (studied both individually and by associating them two by two) was assessed using the kappa concordance index. Sensitivity $(\mathrm{Se})$, specificity $(\mathrm{Sp})$, positive predictive value (PPV), and negative predictive value (NPV) for detection of rectal and sigmoid colon DIE were calculated for all patients included in the study, using a $95 \%$ confidence interval. Statistical analysis was performed using SPSS 23.0 software. $\mathrm{p}<0.05$ was considered statistically significant. 


\section{RESULTS}

Table 1 presents the characteristics of the 49 patients who met the inclusion criteria.

Table 1. Demographic and clinical characteristics of patients

\begin{tabular}{lll}
\hline Parameter & Measurement & Value \\
\hline Age & Mean \pm SD & $31.90 \pm 4.95$ \\
BMI & Mean \pm SD & $23.28 \pm 4.53$ \\
$\quad$ Underweight & $\mathrm{n}(\%)$ & $6(12.2 \%)$ \\
$\quad$ Normal weight & $\mathrm{n}(\%)$ & $27(55.2 \%)$ \\
$\quad$ Overweight & $\mathrm{n}(\%)$ & $13(26.5 \%)$ \\
$\quad$ Obese & $\mathrm{n}(\%)$ & $3(6,1 \%)$ \\
Smoking & $\mathrm{n}(\%)$ & $7(14.9 \%)$ \\
Dysmenorrhea & $\mathrm{n}(\%)$ & $47(95.9 \%)$ \\
Dispareunia & $\mathrm{n}(\%)$ & $41(87.2 \%)$ \\
KESS score & Mean \pm SD & $13.7 \pm 7.63$ \\
GIQLI score & Mean \pm SD & $84.91 \pm 25.84$ \\
Rectal Nodules & $\mathrm{n}(\%)$ & $43(87.8 \%)$ \\
Sigmoid Nodules & $\mathrm{n}(\%)$ & $12(24.5 \%)$ \\
\hline
\end{tabular}

BMI - Body Mass Index, KESS - The Knowles Eccersley Scott Symptom constipation score; GIQLI - Gastrointestinal Quality of Life Index, SD - standard deviation
MRI detected rectal nodules in $75.5 \%$ of patients, ERUS in $71.4 \%$, and CTC in $67.3 \%$. Intraoperatively, $87.8 \%$ of the patients included in the study had rectal nodules. Of the 43 rectal nodules detected intraoperatively, MRI detected 37, resulting that the concordance between intraoperative and MRI results on the existence of rectal nodules is strong $(k=0.602 ; p<0.001)$, for ERUS and CTC respectively the concordances with intraoperative results being moderate $(p<0.001)$ (Table 2).

The concordance is very strong between the intraoperative result and the result of the combined methods, both for MRI OR ERUS and for MRI OR CTC, at least one of the imaging methods identifying every single one of the 43 rectal nodules discovered intraoperatively. The concordance between the intraoperative findings and the CTC OR ERUS results is strong $(k=$ $0.766 ; p<0.001)$, at least one of the 2 imaging methods identifying 40 of the 43 rectal nodules discovered intraoperatively (Table 2).

For the detection of rectal nodules, MRI has the highest Se (86.05\%), followed by ERUS (81.40\%) and CTC (76.74\%). When studying the methods combined, for the detection of rectal nodules, Se was 100\% when MRI was used together with CTC or ERUS and 93.02\% when CTC with ERUS were taken into account. Sp for all three methods is $100 \%$, both studied individually and combined in pairs (Table 2).

Table 2. The value of MRI, ERUS and CTC in detecting rectal nodules

\begin{tabular}{|c|c|c|c|c|c|c|c|c|}
\hline & & \multicolumn{2}{|l|}{10} & \multirow{2}{*}{$\begin{array}{l}k^{*} \\
p \text { value }\end{array}$} & \multirow{2}{*}{$\begin{array}{l}\text { Se (\%) } \\
95 \% \mathrm{Cl}\end{array}$} & \multirow{2}{*}{$\begin{array}{l}\text { Sp (\%) } \\
95 \% \mathrm{Cl}\end{array}$} & \multirow{2}{*}{$\begin{array}{l}\text { PPV (\%) } \\
95 \% \mathrm{Cl}\end{array}$} & \multirow{2}{*}{$\begin{array}{l}\text { NPV (\%) } \\
95 \% \mathrm{Cl}\end{array}$} \\
\hline & & + & - & & & & & \\
\hline \multirow{2}{*}{ MRI } & + & 37 & 0 & \multirow{2}{*}{$\begin{array}{l}0.602 \\
<0.001\end{array}$} & \multirow{2}{*}{$\begin{array}{l}86.05 \\
72.07-94.70\end{array}$} & \multirow{2}{*}{$\begin{array}{l}100.0 \\
54.07-100.0\end{array}$} & \multirow{2}{*}{100.0} & \multirow{2}{*}{$\begin{array}{l}50.0 \\
32.25-67.75\end{array}$} \\
\hline & - & 6 & 6 & & & & & \\
\hline \multirow{2}{*}{ ERUS } & + & 35 & 0 & \multirow{2}{*}{$\begin{array}{l}0.517 \\
<0.001\end{array}$} & \multirow{2}{*}{$\begin{array}{l}81.40 \\
66.60-91.61\end{array}$} & \multirow{2}{*}{$\begin{array}{l}100.0 \\
54.07-100.0\end{array}$} & \multirow{2}{*}{100.0} & \multirow{2}{*}{$\begin{array}{l}42.86 \\
28.64-58.36\end{array}$} \\
\hline & - & 8 & 6 & & & & & \\
\hline \multirow{2}{*}{ стС } & + & 33 & 0 & \multirow{2}{*}{$\begin{array}{l}0.447 \\
<0.001\end{array}$} & \multirow{2}{*}{$\begin{array}{l}76.74 \\
61.37-88.24\end{array}$} & \multirow{2}{*}{$\begin{array}{l}100.0 \\
54.07-100.0\end{array}$} & \multirow{2}{*}{100.0} & \multirow{2}{*}{$\begin{array}{l}37.50 \\
25.85-50.80\end{array}$} \\
\hline & - & 10 & 6 & & & & & \\
\hline \multirow{2}{*}{$\begin{array}{l}\text { MRI OR } \\
\text { ERUS }\end{array}$} & + & 43 & 0 & \multirow{2}{*}{$\begin{array}{l}1.000 \\
<0.001\end{array}$} & \multirow{2}{*}{$\begin{array}{l}100.0 \\
91.78-100.0\end{array}$} & \multirow{2}{*}{$\begin{array}{l}100.0 \\
54.07-100.0\end{array}$} & \multirow{2}{*}{100.0} & \multirow{2}{*}{100.0} \\
\hline & - & 0 & 6 & & & & & \\
\hline \multirow{2}{*}{$\begin{array}{l}\text { MRI OR } \\
\text { CTC }\end{array}$} & + & 43 & 0 & \multirow{2}{*}{$\begin{array}{l}1.000 \\
<0.001 \\
\end{array}$} & \multirow{2}{*}{$\begin{array}{l}100.0 \\
91.78-100.0\end{array}$} & \multirow{2}{*}{$\begin{array}{l}100.0 \\
54.07-100.0 \\
\end{array}$} & \multirow{2}{*}{100.0} & \multirow{2}{*}{100.0} \\
\hline & - & 0 & 6 & & & & & \\
\hline \multirow{2}{*}{$\begin{array}{l}\text { CTC OR } \\
\text { ERUS }\end{array}$} & + & 40 & 0 & \multirow{2}{*}{$\begin{array}{l}0.766 \\
<0.001\end{array}$} & 93.02 & 100.0 & & 66.67 \\
\hline & - & 3 & 6 & & $80.94-98.54$ & $54.07-100.0$ & 100.0 & $40.17-85.63$ \\
\hline
\end{tabular}

$\mathrm{Cl}$ - confidence interval, CTC - computed tomography-based virtual colonoscopy, ERUS - endorectal ultrasonography, IO - intraoperative, $\mathrm{k}$ - Cohen's kappa coefficient, MRI - Magnetic Resonance Imaging, Se - sensibility, Sp - specificity, PPV - positive predictive value, NPV - negative predictive value, *Level of Agreement for kappa value: <0.20 Poor; 0.21-0.40 Fair; 0.41-0.60 Moderate; $0.61-$ 0.80 Strong; $0.81-1.00$ Very strong 
Of the 12 sigmoid nodules found intraoperatively, CTC detected 10 resulting a very strong concordance $(k=0.883 ; p<0.001)$, while MRI detected 5 (moderate concordance, $k=0.422 ; p=0.002$ ) and ERUS 6, the concordance being in this case strong $(k=0.602 ; p$ $<0.001$ ) (Table 3).

In 8 patients out of the 12 with sigmoid nodules, at least one of MRI or ERUS identified the lesions, the concordance being strong $(k=0.649 ; p<0.001)$. In 10 patients, at least one of MRI or CTC showed the existence of sigmoid nodules, the concordance between the intraoperative result and the results of these two imaging methods being strong $(k=0.779 ; p<0.001)$.
In 10 patients, at least one of ERUS or CTC showed the existence of sigmoid nodules which denoted a very strong concordance $(k=0.883 ; p<0.001)$ (Table 3$)$.

CTC has the highest Se for the detection of sigmoid nodules (83.33\%), followed by ERUS (50.00\%) and MRI (41.67\%). The use of two methods of investigation does not increase Se. Sp for ERUS, respectively CTC is $100 \%$, while for MRI is $94.59 \%$. PPV is $100 \%$ for ERUS and CTC, studied both individually and combined. NPV is over $80 \%$ for tests taken individually and increases when using CTC together with one of the other two methods (Table 3 ).

Table 3. The value of MRI, ERUS and CTC in detecting sigmoid nodules

\begin{tabular}{|c|c|c|c|c|c|c|c|c|}
\hline & & \multicolumn{2}{|l|}{10} & \multirow{2}{*}{$\begin{array}{l}k^{*} \\
p \text { value }\end{array}$} & \multirow{2}{*}{$\begin{array}{l}\text { Se (\%) } \\
95 \% \mathrm{Cl}\end{array}$} & \multirow{2}{*}{$\begin{array}{l}\text { Sp (\%) } \\
95 \% \mathrm{Cl}\end{array}$} & \multirow{2}{*}{$\begin{array}{l}\text { PPV (\%) } \\
95 \% \mathrm{Cl} \\
\end{array}$} & \multirow{2}{*}{$\begin{array}{l}\text { NPV (\%) } \\
95 \% \mathrm{Cl} \\
\end{array}$} \\
\hline & & + & - & & & & & \\
\hline \multirow{2}{*}{ MRI } & + & 5 & 2 & 0.422 & 41.67 & 94.59 & 71.43 & 83.33 \\
\hline & - & 7 & 35 & 0.002 & $15.17-72.33$ & $81.81-99.34$ & $35.69-91.84$ & $75.49-89.03$ \\
\hline \multirow{2}{*}{ ERUS } & + & 6 & 0 & 0.602 & 50.00 & 100,0 & \multirow{2}{*}{100.0} & 86.05 \\
\hline & - & 6 & 37 & $<0.001$ & $21.09-78.91$ & $90.51-100.0$ & & $77.79-91.57$ \\
\hline \multirow{2}{*}{ СтC } & + & 10 & 0 & 0.883 & 83.33 & 100,0 & \multirow[t]{2}{*}{100.0} & 94.87 \\
\hline & - & 2 & 37 & $<0.001$ & $51.59-97.91$ & $90.51-100.0$ & & $83.92-98.50$ \\
\hline MRI OR & + & 8 & 2 & 0.649 & 66.67 & 94.59 & 80.00 & 89.74 \\
\hline ERUS & - & 4 & 35 & $<0.001$ & $34.89-90.08$ & $81.81-99.34$ & $49.51-94.23$ & $79.66-95.13$ \\
\hline MRI OR & + & 10 & 2 & 0.779 & 83.33 & 94.59 & 83.33 & 94.59 \\
\hline CTC & - & 2 & 35 & $<0.001$ & $51.59-97.91$ & $81.81-99.34$ & $55.92-95.17$ & $83.13-98.42$ \\
\hline CTC OR & + & 10 & 0 & 0.883 & 83.33 & 100.0 & \multirow{2}{*}{100.0} & 94.87 \\
\hline ERUS & - & 2 & 37 & $<0.001$ & $51.59-97.91$ & $90.51-100.0$ & & $83.92-98.50$ \\
\hline
\end{tabular}

$\mathrm{Cl}$ - confidence interval, CTC - computed tomography-based virtual colonoscopy, ERUS - endorectal ultrasonography, IO - intraoperative, k - Cohen's kappa coefficient, MRI - Magnetic Resonance Imaging, Se - sensibility, Sp - specificity, PPV - positive predictive value, NPV - negative predictive value, *Level of Agreement for kappa value: <0.20 Poor; $0.21-0.40$ Fair; $0.41-0.60$ Moderate; $0.61-0.80$ Strong; $0.81-1.00$ Very strong

$10.2 \%(\mathrm{n}=5)$ of the patients included in the research have a second rectal nodule. MRI identified the second rectal nodule in $8.2 \%$ of patients $(\mathrm{n}=4, k=$ $0.878 ; p<0.001)$, ERUS in 2.0\% ( $\mathrm{n}=1, k=0.310 ; p=$ $0.003)$ and CTC in $10.2 \%$ of patients $(\mathrm{n}=4, k=0.777$; $p<0.001)$.

$4.1 \%(n=2)$ of the patients included in the research have a second sigmoid nodule. CTC revealed the second sigmoid nodule in $4.1 \%(\mathrm{n}=2)$ of patients, MRI in $2.0 \%(\mathrm{n}=1, k=0.657 ; p<0.001)$ and ERUS in none of them. CTC detected the second sigmoid nodule in one of the 2 patients in whom were detected intraoperatively and found a second sigmoid nodule in a patient who did not have two sigmoid nodules intraoperatively, so the concordance of intraoperative findings and CTC results is moderate $(k=0.459 ; p<0.001)$.

Table 4 sums up the results regarding the characteristics of the intestinal lesions.

In establishing the depth of the rectal nodules, ERUS has the best concordance. It showed the correct depth for 28 of the 35 rectal nodules found intraoperatively (moderate concordance, $k=0.550 ; p=0.001$ ). 
Of the 33 rectal nodules detected using CTC, 23 are located in the muscularis propria layer (correct depth in 23 patients) and 10 are located in the submucosa layer (CTC does not show the correct depth in any patient). Thus, the concordance between the intraoperative findings and CTC results regarding the depth of the rectal nodules cannot be calculated. None of the imaging methods studied assessed satisfactorily the depth in the case of sigmoid nodules.

None of the methods proved itself useful in assessing the width of the rectal nodules, between the intraoperative results and those of the imaging method being a very poor concordance for MRI and poor for ERUS, respectively CTC. Regarding the width of the sigmoid nodules, there is no concordance with the intraoperative results for any of the imaging methods.

Rectal nodules stenosis is best evaluated by CTC (moderate concordance, $k=0.540, p<0.001$ ), for MRI and ERUS the concordances being very weak. Regarding the stenosis of sigmoid nodules, however, there is a very strong concordance, with statistical significance $(k=1.000 ; p<0.001)$ between intraoperative findings and CTC results, while for MRI and ERUS the concordance is very weak and weak, respectively, without statistical significance.

The height of rectal nodules, although slightly overestimated, was best determined by MRI ( $83.35 \pm$ $40.80 \mathrm{~mm}$ vs. $81.62 \pm 25.00 \mathrm{~mm}, p=0.761)$, being underestimated by ERUS $(72.29 \pm 21.84 \mathrm{~mm}$ vs. 82.86 $\pm 26.85 \mathrm{~mm}, p=0.009)$, and overestimated by CTC $(93.79 \pm 43.86 \mathrm{~mm}$ vs. $80.30 \pm 26.74 \mathrm{~mm}, p=0.030)$. The height of the sigmoid nodules compared to the intraoperative results is underestimated by MRI (118.00 $\pm 124.98 \mathrm{~mm}$ vs. $143.00 \pm 73.62 \mathrm{~mm}, p=0.603)$ and ERUS $(110.00 \pm 71.27 \mathrm{~mm}$ vs. $188,33 \pm 45.78 \mathrm{~mm}, p$ $=0.032)$ and overestimated by CTC $(193.10 \pm 71.06$ $\mathrm{mm}$ vs. $168.50 \pm 61.91 \mathrm{~mm}, p=0.075)$.

The average length of nodules, although slightly underestimated, is best appreciated by CTC for both rec$\operatorname{tal}(31.79 \pm 27.52 \mathrm{~mm}$ vs. $33.02 \pm 15.32 \mathrm{~mm}, p=0.704)$ and sigmoid nodules $(38.00 \pm 20.57 \mathrm{~mm}$ vs. $40.50 \pm$ $25.86 \mathrm{~mm}, p=0.775)$.

Table 4. Characteristics of intestinal endometriotic nodules

\begin{tabular}{|c|c|c|c|c|}
\hline & & \multirow{2}{*}{\multicolumn{3}{|c|}{ Imagistic method }} \\
\hline & & & & \\
\hline & & MRI & ERUS & CTC \\
\hline \multicolumn{5}{|c|}{ Rectal nodules } \\
\hline D & $k^{*}$ & $0.026(p=0.839)$ & $0.550(p=0.001)$ & - \\
\hline W & $k^{*}$ & $0.127(p=0.189)$ & $0.290(p=0.046)$ & $0.203(p=0.041)$ \\
\hline$S$ & $k^{*}$ & $0.165(p=0.058)$ & $0.036(p=0.568)$ & $0.540(p<0.001)$ \\
\hline $\mathbf{L}$ & $\begin{array}{l}\text { Mean } \pm \text { SD } \\
\mathrm{IM} / \mathrm{IO}\end{array}$ & $\begin{array}{l}36.95 \pm 27.22 / \\
33.65 \pm 15.3 \\
(p=0.458)\end{array}$ & $\begin{array}{l}29.06 \pm 22.76 / 32.86 \pm 14.96 \\
(p=0.251)\end{array}$ & $\begin{array}{l}31.79 \pm 27.52 / 33.02 \pm 15.32 \\
(p=0.704)\end{array}$ \\
\hline $\mathbf{H}$ & $\begin{array}{l}\text { Mean } \pm \text { SD } \\
\mathrm{IM} / \mathrm{IO}\end{array}$ & $\begin{array}{l}83.35 \pm 40.80 / 81.62 \pm 25.00 \\
(p=0.761)\end{array}$ & $\begin{array}{l}72.29 \pm 21.84 / 82.86 \pm 26.85 \\
(p=0.009)\end{array}$ & $\begin{array}{l}93.79 \pm 43.86 / 80.30 \pm 26.74 \\
(p=0.030)\end{array}$ \\
\hline \multicolumn{5}{|c|}{ Sigmoid nodules } \\
\hline D & $k^{*}$ & $0.286(p=0,361)$ & $0.143(p=0.649)$ & - \\
\hline W & $k^{*}$ & $0.000(p=1,000)$ & $-0.143(p=0.615)$ & $-0.023(p=0.725)$ \\
\hline $\mathbf{S}$ & $k^{*}$ & $0.167(p=0,464)$ & $0.308(p=0,198)$ & $1.000(p<0.001)$ \\
\hline $\mathbf{L}$ & $\begin{array}{l}\text { Mean } \pm \text { SD } \\
\mathrm{IM} / \mathrm{IO}\end{array}$ & $\begin{array}{l}38.40 \pm 18,78 / 55.00 \pm 30,82 \\
(p=0.086)\end{array}$ & $\begin{array}{l}10.83 \pm 18.55 / 46.66 \pm 31.41 \\
(p=0.091)\end{array}$ & $\begin{array}{l}38.00 \pm 20.57 / 40.50 \pm 25.86 \\
(p=0.775)\end{array}$ \\
\hline $\mathbf{H}$ & $\begin{array}{l}\text { Mean } \pm S D \\
\mathrm{IM} / \mathrm{IO}\end{array}$ & $\begin{array}{l}118.00 \pm 124.98 / 143.00 \pm 73.62 \\
(p=0.603)\end{array}$ & $\begin{array}{l}110.00 \pm 71.27 / 188.33 \pm 45.78 \\
(p=0.032)\end{array}$ & $\begin{array}{l}193.10 \pm 71.06 / 168.50 \pm 61.91 \\
(p=0.075)\end{array}$ \\
\hline
\end{tabular}

CTC - computed tomography-based virtual colonoscopy, ERUS - endorectal ultrasonography, D - depth, W - Width, S - stenosis, L - length, H - height, IM / IO - imagistic method results / intraoperative findings, $k$ - Cohen's kappa coefficient, MRI - Magnetic Resonance Imaging, *Level of Agreement for kappa value: < 0.20 Poor; $0.21-0.40$ Fair; $0.41-0.60$ Moderate; $0.61-0.80$ Strong; $0.81-1.00$ Very strong. 


\section{DISCUSSIONS}

Given that an early diagnosis of DIE is crucial when taking into consideration the fertility and quality of life of patients, that it is invasive requiring laparoscopic biopsy accompanied by histopathological examination, and that some preoperative planning is necessary, in the present study we investigated the usefulness of 3 non-invasive imaging methods for this pathology's diagnosis, respectively MRI, ERUS and CTC.

TVUS is considered the first-line imaging technique in the evaluation of any type of DIE lesions, including colorectal, being an imagistic method easily accepted, very accessible and with high accuracy, however TVUS is not helpful in evaluating lesions located proximal to rectosigmoid junction, thus justifying the use of MRI in the mapping of potential endometriotic lesions ${ }^{4,7}$.

Thus, MRI together with ERUS and CTC are non-invasive imaging methods that can be used preoperatively, mentioning though, that for any of them, the experience of the evaluator in recognizing DIE is very important.

Alborzi et al. (2018) also concluded that, after TVUS, MRI should be the preferred imaging method in the evaluation of patients suspected of presenting DIE lesions. Agreeing with the mentioned authors, we started the preoperative imaging evaluation of patients using the MRI, a method that in this study proved to have a strong concordance for detecting rectal nodules and a moderate one for sigmoid nodules. MRI indicated in our case the presence of 2 sigmoid nodules that were not found intraoperatively. Darai et al. (2018) deduced that a negative pelvic MRI allows the exclusion of DIE with a performance similar to surgery, but a positive MRI is less accurate than surgery due to a large number of false positive results $(23 \%)^{8}$.

The first comprehensive description of the diagnostic value of MRI for pelvic endometriosis was performed in 2004. It was a prospective bicentric study that included 195 patients with histological evidence of the presence of endometriotic implants, and showed, for a specialized team, an excellent diagnostic performance of this technique with $\mathrm{Se}$ and $\mathrm{Sp}$ values of $90 \%$ and $91 \%$ respectively ${ }^{9}$. A meta-analysis published 10 years later evaluating 20 studies, most of them prospective, which included 1819 patients with histopathologically confirmed endometriosis, found for MRI, a Se of $83 \%$ and a Sp of $90 \%{ }^{10}$.
ERUS was initially used for the evaluation of the prostate and then adapted for the evaluation of rectal and perirectal lesions, first for the staging of rectal cancer, and, in 1993, it began being used for the evaluation of recto-sigmoid endometriosis ${ }^{11,12}$.

When studying a group $(\mathrm{n}=127)$ constituted similarly to the one in the present study, Roman et al. (2016) found, for the detection of rectal nodules the following values: for MRI Se 59.3\%, Sp 33.3\%, for ERUS: Se 86\%, Sp 58.8\%, and for CTC: Se 97.2\%, Sp $84.2 \%{ }^{13}$. Earlier even, Chapron et al. (2004), retrospectively studying a monocentric series of 81 consecutive patients, showed the superiority of ERUS in the detection of rectal lesions (Se 97.1\%, Sp 89.4\%) compared to pelvic MRI (Se 76.5\%, Sp 97.9\%) ${ }^{14}$. In the present study, however, MRI had the highest Se for the detection of rectal nodules (86.05\%).

Regarding the detection of sigmoid nodules, Roman et al. (2016) found the following values: for CTC Se 92.6\%, Sp 87.7\%, PPV 84.8\%, NPV 94.1\%, for ERUS Se 16.7\%, Sp 98.5\%, PPV 87.5\%, NPV 65.7\%, and for MRI Se 59.3\%, Sp 84.9\%, PPV 71.1\%, NPV 72.8\% ${ }^{13}$, in the present study CTC also having the highest Se for detecting sigmoid nodules, although lower than that reported by the aforementioned authors.

Mehedinţu et al. (2018), in a study that included 71 patients who received surgical treatment for colorectal DIE, who were evaluated preoperatively by MRI followed by CTC, deduced the following: the concordance between intraoperative findings and preoperative information provided by MRI and CTC in regarding the presence of rectal nodules was strong; CTC was effective in determining the degree of stenosis for rectal nodules; for sigmoid nodules, intraoperative and CTC results showed moderate concordance; CTC has a higher accuracy than MRI in diagnosing sigmoid nodules ${ }^{15}$. In our study, the concordance with the intraoperative findings regarding the existence of rectal nodules was very strong when we considered the results of MRI OR ERUS, or those of MRI OR CTC, Se reaching in both situations $100 \%$. In the case of sigmoid nodules, however, there was a very strong concordance between the intraoperative results and those provided by ERUS OR CTC, and taking the methods individually, CTC also had the highest accuracy in detecting sigmoid lesions.

When it comes to surgically treating intestinal DIE, colorectal resection of the affected segment or excision of the nodule may be used, the last one either without 
opening the lumen (shaving) or by doing so (full thickness or disc excision $)^{5}$.

When choosing the surgical approach, it is important to know, not only the location of the lesions (height), but also the dimensions of the nodules, respectively their widths and lengths, the degree of stenosis they generate and the layer into which the lesions penetrate (muscularis propria, submucosa, mucosa). Knowing these aspects allows preoperative planning, with the establishment of a multidisciplinary team when it is suspected that the help of the colorectal surgeon may be necessary, as well as correct information of the patient in order to obtain consent, taking into account that the risk of complications varies from technique to technique.

Similar to evaluating the infiltration of the rectal wall in rectal cancer, Roman et al. (2008) used ERUS in assessing the depth of parietal infiltration in rectal DIE, the data obtained by them showing that the method has a low accuracy in detecting mucosal and submucosal infiltration in endometriosis ${ }^{16}$. However, Darai et al. (2018) stated that, in terms of rectosigmoid muscle infiltration, ERUS is more effective than MRI, recommending the inclusion of the method in the preoperative evaluation of patients with $\mathrm{DIE}^{8}$. In the present study, ERUS shows moderate concordance in detecting the depth of the rectal nodules.

Although, according to the specialty literature, MRI is the most useful tool in the mapping of pelvic endometriosis, including DIE nodules of the uterosacral ligaments, ovarian endometriomas, fallopian tubes abnormalities and associated adenomyosis ${ }^{17}$, CTC provides a better assessment of the impact of intestinal DIE, and should be considered complementary to MRI ${ }^{13}$. It may play an important role in assessing digestive tract stenosis, rectal wall involvement, the height at which the rectal nodule is located, and the feasibility of rectal shaving when choosing to preserve the rectum ${ }^{18}$. In the present study also, CTC proved itself useful in evaluating the stenosis given by endometriotic lesions, especially for sigmoid nodules where the concordance of the method was very strong.

Lumen stenosis is best evaluated by CTC, on one hand due to the expansion of the intestinal lumen by the insufflation of $\mathrm{CO} 2$, and, on the other hand, due to the evaluation performed in both dorsal and ventral decubitus ${ }^{13}$. MRI with the ,jelly method" protocol is very useful, but only for rectal nodules and those of the distal sigmoid ${ }^{19}$, which is also supported by our results ac- cording to which the concordance was moderate for the detection of sigmoid nodules, and strong for rectal nodules. ERUS can detect intestinal lumen stenosis when probe progression becomes impossible or very painful, but its usefulness is again limited for sigmoid nodules, even if they are more frequently responsible for occlusion / sub-occlusion and not rectal ones ${ }^{20}$. Regarding rectal examination, its utility is extremely limited, this method being able to detect only infiltrations involving the middle and distal portions of the rectum ${ }^{13}$.

Also, the information provided by CTC can help establish the feasibility of trans-anal disc excision, which is dependent on the length and height of rectal infiltration and can be performed in the case of nodules with a maximum diameter of $5 \mathrm{~cm}$ and a maximum height of $10 \mathrm{~cm}^{5,21}$. This technique is preferred, whenever it can be performed, since it has multiple advantages: it allows the elimination of digestive symptoms and prevents rectal stenosis, as well as postoperative dysfunctions associated with the removal of the middle and distal rectum ${ }^{5}$.

At the same time, the identification of intestinal DIE lesions by the CTC performed preoperatively can eliminate the risk that some lesions go unnoticed during laparoscopic evaluation. In addition, preoperative identification of lesions allows us to correctly inform the patient about the likelihood of the need for multiple excisions or resections that could involve performing an ileostomy.

Thus, since none of the diagnostic imaging methods is perfect in detecting DIE, we believe that, while MRI evaluation should never miss from the evaluation preceding surgery, associating to it both CTC and ERUS, can bring important additions to the preoperative diagnosis, provided that the evaluations are performed by experienced personnel.

Some of the results obtained have only clinical significance, lacking statistical significance, which reveals that, in order to obtain statistically significant results, it is recommended to repeat or continue the study on a larger population.

Compliance with ethics requirements: The authors declare no conflict of interest regarding this article. The authors declare that all the procedures and experiments of this study respect the ethical standards in the Helsinki Declaration of 1975, as revised in 2008(5), as well as the national law. Informed consent was obtained from all the patients included in the study. 


\section{References}

1. Hwang $H$, Chung $Y$ J, Lee SR, Park HT, Song JY, Kim H, Lee DY, Lee EJ, Kim MR, Oh ST. Clinical evaluation and management of endometriosis: guideline for Korean patients from Korean Society of Endometriosis. Obstet Gynecol Sci. 2018 Sep;61(5):553-564. doi: 10.5468/ogs.2018.61.5.553.

2. Audebert A, Petousis S, Margioula-Siarkou C, Ravanos K, Prapas N, Prapas Y. Anatomic distribution of endometriosis: A reappraisal based on series of 1101 patients. Eur J Obstet Gynecol Reprod Biol. 2018 Sep 5;230:36-40. doi: 10.1016/j.ejogrb.2018.09.001. [Epub ahead of print]

3. Guerriero S, Ajossa S, Minguez JA, Jurado M, Mais V, Melis GB, Alcazar JL. Accuracy of transvaginal ultrasound for diagnosis of deep endometriosis in uterosacral ligaments, rectovaginal septum, vagina and bladder: systematic review and meta-analysis. Ultrasound Obstet Gynecol. 2015 Nov;46(5):534-45. doi: 10.1002/uog.15667.

4. Alborzi S, Rasekhi A, Shomali Z, Madadi G, Alborzi M, Kazemi M, Hosseini Nohandani A. Diagnostic accuracy of magnetic resonance imaging, transvaginal, and transrectal ultrasonography in deep infiltrating endometriosis. Medicine (Baltimore). 2018 Feb. ; 97(8):e9536.

5. Bridoux V, Roman H, Kianifard B, Vassilieff M, Marpeau L, Michot $F$, et al. Combined transanal and laparoscopic approach for the treatment of deep endometriosis infiltrating the rectum. Hum Reprod 2012;27:418-26.

6. Nisenblat V, Bossuyt PMM, Farquhar C, Johnson N, Hull ML. Imaging modalities for the non-invasive diagnosis of endometriosis. Cochrane Database of Systematic Reviews. 2016; 2:1-297.

7. Belghiti J, Thomassin-Naggara I, Zacharopoulou C, Zilberman S, Jarboui L, Bazot M, et al. Contribution of computed tomography enema and magnetic resonance imaging to diagnose multifocal and multicentric bowel lesions in patients with colorectal endometriosis. J Minim Invasive Gynecol 2015;22(5):776-84.

8. Thomassin-Naggara I, Bendifallah S, Rousset P, Bazot M, Ballester M, Darai E. Performances et critères de qualité de l'IRM, du colo-scanner,de l'entéro IRM/CT pour le diagnostic d'endométriose pelvienne, RPC Endométriose CNGOF-HAS. Gynecol Obstet Fertil Senol. 2018 Mar;46(3):177-184. doi: 10.1016/j.gofs.2018.02.023.

9. Bazot M, Darai E, Hourani R, Thomassin I, Cortez A, Uzan S, et al. Deep pelvic endometriosis: MR imaging for diagnosis and prediction of extension of disease. Radiology 2004;232(2):379-89.

10. Medeiros LR, Rosa MI, Silva BR, Reis ME, Simon CS, Dondossola $E R$, et al. Accuracy of magnetic resonance in deeply infiltrating endometriosis: a systematic review and meta-analysis. Arch Gynecol Obstet 2015;291(3):611-21.
11. St Ville EW, Jafri SZ, Madrazo BL, Mezwa DG, Bree RL, Rosenberg BF. Endorectal sonography in the evaluation of rectal and perirectal disease. AJR Am J Roentgenol. 1991 Sep;157(3):503-8.

12. Berceanu C, Brătilă E, Cirstoiu MM, Mehedințu C. Endometrioza. Ed. Medicala Universitara Craiova. 2018. 6:113-132

13. Roman H, Carilho J, Da Costa C, De Vecchi C, Suaud O, Monroc M, Hochain P, Vassilieff M, Savoye-Collet C, Saint-Ghislain M. Computed tomography-based virtual colonoscopy in the assessment of bowel endometriosis: The surgeon's point of view. Gynecol Obstet Fertil. 2016 Jan;44(1):3-10. doi: 10.1016/j.gyobfe.2015.11.008

14. Chapron C, Vieira M, Chopin N, Balleyguier C, Barakat H, Dumontier I, et al. Accuracy of rectal endoscopic ultrasonography and magnetic resonance imaging in the diagnosis of rectal involvement for patients presenting with deeply infil-trating endometriosis. Ultrasound Obstet Gynecol 2004;24(2):175-9.

15. Mehedințu $C$, Brîndușe LA, Brătilă $E$, Monroc $M$, Lemercier $E$, Suaud O, Collet-Savoye C, Roman H. Does Computed Tomography-Based Virtual Colonoscopy Improve the Accuracy of Preoperative Assessment Based on Magnetic Resonance Imaging in Women Managed for Colorectal Endometriosis? J Minim Invasive Gynecol. 2018 Sep - Oct;25(6):1009-1017. doi: 10.1016/j. jmig.2018.01.019

16. Roman H, Kouteich K, Gromez A, Hochain P, Resch B, Marpeau L. Endorectal ultrasound accuracy in the diagnosis of rectal endometriosis infiltration depth. Fertil Steril. 2008 Oct;90(4):1008-13.

17. Bazot M, Bornier C, Dubernard G, Roseau G, Cortez A, Daraï E. Accuracy of magnetic resonance imaging and rectal endoscopic sonography for the prediction of location of deep pelvic endometriosis. Hum Reprod. 2007 May;22(5):1457-63.

18. Roman H. Deep rectal shaving using plasma energy for endometriosis causing rectal stenosis. Colorectal Dis 2014;16:834-6.

19. Biscaldi E, Ferrero S, Leone Roberti Maggiore U, Remorgida $V_{\text {, }}$ Venturini PL, Rollandi GA. Multidetector computerized tomography enema versus magnetic resonance enema in the diagnosis of rectosigmoid endometriosis. Eur J Radiol 2014;83:261-7.

20. Roman H, Puscasiu L, Lempicki M, Huet E, Chati R, Bridoux V, et al. Colorectal endometriosis responsible for bowel occlusion or sub-occlusion in women with pregnancy intention: is the policy of primary IVF always safe? J Minim Invasive Gynecol 2015;22:1059-67.

21. Roman H, Abo C, Huet E, Bridoux V, Auber M, Oden S, et al. Full thickness disc excision in deep endometriotic nodules of the rectum. A prospective cohort. Dis Colon Rectum 2015;58:957-66. 